The book begins by pointing out that the nature of disease is always changing and that this constant change is part of our social history. An infective disease, once it is established, Prof. Lovell reminds us, may stay with us for good and he gives us evidence of this. Discussing next the normal bacterial flora of man and other animals, and the phenomena of resistance (immunity) to disease, he goes on to discuss the host-parasite relationship, which, like disease, is never stable, a fact which is, in spite of Lovell's view to the contrary, very well realized nowadays.

In Part 2 of the book the author discusses various subsidiary factors which play a part in infective disease. Thus the influence of age is illustrated by reference to white scours of calves, infantile diarrhœa, lamb dysentery, Johne's disease of cattle, meningitis in children, diphtheria, scarlet fever, leptospiral infections and various viral diseases, including poliomyelitis. The significance of sex is illustrated by reference to mastitis and pyelonephritis of cattle, trichomoniasis, tuberculosis, brucellosis and other infections. The effects of changes in the host's diet are illustrated by reference to botulism, food poisoning by Salmonella, enterotoxæmia of lambs and protein deficiencies and those due to changes in husbandry and environment, by tuberculosis, the slow pneumonia of sheep in Iceland called 'maedi' and by Johne's disease of cattle and braxy of sheep. Fungal infections are considered under the heading of the effects of the general health of the host. In an interesting section on the effects of trauma the author discusses tetanus, gas gangrene and infections with various species of Clostridium and those due to the bites of animals, such as rabies. The effects of stress and fatigue and the use of properdin and adrenocorticoids for the treatment of them are then considered, and a final section discusses infections which involve a living vector as well as a pathogen, the diseases here discussed including rickettsial and viral infections, influenza of man and swine, louping ill, foot and mouth disease, yellow fever, psittacosis, $Q$ fever, distemper of dogs and the different distemper of cats and other infections. A brief bibliography gives references to standard works.

Both the veterinarian and the student of human disease will learn much from this book, and it will, as its author commendably intends, make him discard any tendency he may have to think of each disease as a separate entity.

G. LAPAge

\section{A TREATISE ON STATICALLY INDETERMINATE STRUCTURES}

Hyperstatic Structures

An Introduction to the Theory of Statically Indeterminate Structures, Vol. 1. By Prof. J. A. L. Matheson. With chapters by Dr. N. W. Murray and Dr. R. K. Livesley. Pp. xv +474. (London: Butterworths Scientific Publications, 1959.) 90s.

WHE student of that branch of elasticity which deals with structural mechanics too often finds himself confused by the numerous 'theorems' and 'principles' which so liberally ornament the literature of the subject. This confusion is worse confounded by the use of various names for the same result, and even, on occasion, the appropriation of a well-established designation for something quite different.
In fact the number of independent principles which are of value to the engineer are surprisingly small, and even if the subject is approached from a purely academic point of view rather than from a more practical one, that number is not greatly increased. Many of the results which are so frequently stated as principles are in fact variations, often obvious ones, of fundamental theorems. These variations may, indeed, prove very useful in particular applications, but their isolation from the fundamentals on which they are based makes for an artificial elaboration of the subject and the consequent bedevilment of the student.

One of the avowed objects of the author of this book is to clarify this position and to show the interrelationship of the many theorems and methods commonly quoted. The result will be of considerable interest to the reader who already has a working knowledge of the subject ; but the word "introduction" in the title may prove somewhat misleading and even disheartening to the real beginner.

In the preface the author says that the book is an attempt to produce the treatise (incidentally a much better description of the work than is indicated by the title) which his friends hoped that the late Prof. Cyril Batho would write. Batho had an extensive knowledge of German literature on theory of structures and a great admiration for the work of Mueller. Breslau in particular, and his friends will be in no doubt that he would have been pleased by Prof. Matheson's treatment. This comment, however. does only partial justice to Matheson; in addition to the careful presentation of the classical work of Clerk Maxwell, Mohr, Castigliano, Williot and MuellerBreslau there is much which could not have been found in a book by Batho, for even in the few years since his death considerable advances have been made. References to the work of David Williams, E. H. Brown and others in clarifying the relationship between the different energy theorems, and the specialized chapters on the stability of struts and frameworks, and on matrix methods of analysis, by N. W. Murray and R. K. Livesley respectively, indicate the up-to-date character of the book.

In this connexion, too, the inclusion of a short account of the work of Prof. J. F. Baker and his colleagues at Cambridge is to be welcomed as an outline of the latest trends in steel structural design based on collapse loads; the possibility suggested by the author that this reference may be out of place in a work dealing with elastic structures surely need not be considered seriously. Flastic and plastic behaviour are both phenomena with which the engineer has to deal, and any attempt at a complete separation of their study can only lead to an unbalanced outlook.

A suggestion for future editions which might be offered is that the section of Chapter 1 which deals with intuitive methods for the approximate solution of statically indeterminate problems should be relegated to an appendix. It is undoubtedly true that a visualization of displacements can materially assist the analysis of a structure, but it is equally true that intuition can come only as a result of experience and knowledge, and to suggest some of the ideas contained in this section at such an early stage may prove a disservice to the student rather than a help.

The book is excellently produced, and with its companion volume of examples which is promised for a later date will add something distinctive to British literature in theory of structures. One wishes it the success which it merits. A. J. S. PIPPARD 